\title{
Registration and timely dissemination of clinical trials and results
}

Clinical research in human subjects has progressed, and major advances have been made over time in relation to study design, development, and monitoring for the purpose of protecting participants. This has led to very important scientific advances in different fields, such as health care procedures and interventions, and disease diagnosis, treatment and prevention. However, there is still plenty of room for improvement.

One of the main aspects related to improving transparency in clinical research is the timely dissemination of clinical trials and results.

Both healthy and ill people who take part in scientific research in a voluntary and altruistic manner expect that data obtained based on their participation will help to improve public health. Clinical investigators become morally and ethically committed to such contribution when, at the time of obtaining the informed consent from participants, they explain that the study may not have direct benefits for participants but may help to improve knowledge on the disease under study or its treatment and that subjects will have access to results.

In 2000, the US National Institutes of Health (NIH) established ClinicalTrials.gov, a publicly available database for the registration of research studies in human subjects. More than 228574 studies have been registered since the site was launched. ${ }^{1}$ Information on registered studies include a description of the study drug, device or procedure status, the study objectives, participant inclusion criteria, study site location, name of investigators in charge of study sites, and the interventions to be performed, etc.

Why register a research study? In the beginning, the ClinicalTrials.gov database was the result of the need to publish basic information on ongoing clinical trials regarding certain diseases so that potential participants would know about them. Since 2007, registering a study and its results became a regulatory requirement for phase 2 and 3 clinical trials prior to submission for a new drug marketing authorization to the Food and Drug Administration (FDA). At present, the registration has extended to all clinical-pharmacological, biotechnological, and observational studies.

In addition, article 35 of the Declaration of
Helsinki (latest version: October 2013) states: "Every research study involving human subjects must be registered in a publicly accessible database before recruitment of the first subject" ${ }^{2}$

Other organizations also request the registration of research studies in human subjects in a publicly available database before recruitment of the first subject, such as the World Health Organization (WHO) International Clinical Trials Registry Platform (made up of the national registries of Germany, Australia-New Zealand, the Netherlands, India, China, Japan, and Brazil, among others). ${ }^{3}$

In Argentina, there are several publicly accessible registries for clinical and pharmacological studies. On the one hand, there are provincial registries (for the assessment and audit of health research) in Córdoba, Mendoza, Neuquén and Buenos Aires, among others provinces. On the other hand, at the national level, there is the National Registry of Health Research (Registro Nacional de Investigaciones en Salud, RENIS), created by resolution of the Ministry of Health number 1480/2011 within the scope of the National Health Research Committee (Comisión Nacional de Salud Investiga), which includes information about the study, the ethics committee, the study sites, and the sponsors of health research studies conducted in Argentina. As stated on their website: "The objective of this organization is to include in its database all health research studies conducted in Argentina in order to facilitate database lookup and provide the public with updated information on health research studies conducted, funded, or regulated by the Ministry of Health and its dependent decentralized agencies. Making results available for the society favors the development of health policies, prevents effort duplication, and encourages research transparency". ${ }^{4}$

In addition to registration, it is mandatory for all studies registered in ClinicalTrials.gov to submit complete (primary and secondary) results, ${ }_{1}$ including negative or non-conclusive findings, to reduce duplication of studies or strategies that showed no benefits and to protect research participants. In 2005, the International Committee of Medical Journal Editors (ICMJE) established the registration of clinical trials (phases 1-4) in a publicly renowned registry to consider their 
potential for publication. ${ }^{5}$ Archivos Argentinos de Pediatría adheres to this policy; its publication rules strongly recommend that clinical trials be registered in one of the registries recognized by the WHO. ${ }^{6}$

In spite of the above information, hundreds of clinical studies conducted worldwide have never been presented or results have not been made public. A recent study on 400 clinical studies registered in ClinicalTrials.gov indicated that the authors of $30 \%$ had not published results in any journal or in the results database within 4 years after study completion. ${ }^{7}$

Another study assessed 489 observational studies whose safety results had been registered inClinicalTrials.gov and showed that the authors of only $189(39 \%)$ had published their findings at least 30 months after study completion; among 158 studies that had not been published, the results of $31 \%$ had been submitted to ClinicalTrials.gov, and $21 \%$ had been presented only in the sponsor's website. $^{8}$

In a recent report, the $\mathrm{WHO}$ requested more transparency in clinical research after indicating that among clinical trials of vaccines against 5 diseases registered in a variety of databases between 2006 and 2012, only 29\% had been published in a peer-reviewed journal by the WHO recommended deadline of 24 months following study completion. ${ }^{9}$

Based on recognition of these problems, and in accordance with the purpose of making research transparent and keeping people's trust, the NIH (the largest public funder of clinical trials in the US), together with the FDA, has published a series of measures (final rule) which will be valid as of 2017 to promote the registration and timely dissemination of results of all clinical trials funded with taxpayers' money. ${ }^{10}$

In the short run, it is expected that the publication and/or presentation of results from clinical trials registered in a publicly accessible database will become part of the routine and that; by means of a greater level of transparency, plagiarism, fraud, fragmentation, and data duplication will be prevented. Patients will not be exposed to studies or strategies that are risky or have already been tested, and research resources/ costs will be correctly administered in the best interest of society and the scientific community.

Adriana Aguilar, M.D. Assistant Editor aaguilar.publicaciones@sap.org.ar

http:/ /dx.doi.org/10.5546/aap.2017.eng.2

\section{REFERENCES}

1. ClinicalTrials.gov. [Accessed on:October $25^{\text {th }}, 2016$ ] Available at: https://clinicaltrials.gov/

2. Declaración de Helsinki de la AMM. Principios éticos para las investigaciones médicas en seres humanos. [Accessed on: October 27 $\left.7^{\text {th }}, 2016\right]$ Available at: http://www.wma. net/es/30publications/10policies/b3/

3. WHO International Clinical Trials Registry Platform. [Accessed on: October 23 $\left.{ }^{\text {rd }}, 2016\right]$. Available at:http:// www.who.int/ictrp/en/

4. Registro Nacional de Investigaciones en Salud-RENIS. [Accessed on: October $16^{\text {th }}, 2016$ ] Available at:https: / / sisa. msal.gov.ar/sisa/sisadoc/docs/050104/renis_intro.jsp

5. ICMJE.Clinical Trials Registration. [Accessed on: October 28th, 2016]. Available at:http://icmje.org/about-icmje/ faqs/clinical-trials-registration/

6. Archivos Argentinos de Pediatría. Reglamento de publicaciones. [Accessed on: October $28^{\text {th }}, 2016$ ] Available at: http:/ / www.wsap.org.ar/archivos

7. Saito H, Gill CJ (2014) How Frequently Do the Results from Completed US Clinical Trials Enter the Public Domain? A Statistical Analysis of the ClinicalTrials.gov Database. PLoS ONE 9(7): e101826. doi:10.1371/journal.pone.0101826

8. Baudart M, Ravaud P, Baron G, Dechartres A, et al. Public availability of results of observational studies evaluating an intervention registered at ClinicalTrials.gov. BMC Med 2016;14:7.

9. La OMS pide más transparencia en la investigación médica. [Accessed on: October 28 ${ }^{\text {th }}, 2016$ ] Available at:http://www.who.int/mediacentre/news/notes/2015/ medical-research-transparency / es/https: / /www.nih. gov/news-events/news-releases/hhs-take-steps-providemore-information-about-clinical-trials-public

10. Hudson KL, Lauer MS, Colins FS. Toward a New Era of Trust and Transparency in Clinical Trials. JAMA 2016;316 (13):1353-1354. 